\title{
Tolerability to high doses of formoterol and terbutaline via Turbuhaler® for 3 days in stable asthmatic patients
}

\author{
K.J. Tötterman*, L. Huhti*, E. Sutinen*, R. Backman*, A. Pietinalho*, \\ M. Falck+, P. Larsson+, O. Selroos*,+
}

Tolerability to high doses of formoterol and terbutaline via Turbuhaler ${ }^{\circledR}$ for 3 days in stable asthmatic patients. K.J. Tötterman, L. Huhti, E. Sutinen, R. Backman, A. Pietinalho, M. Falck, P. Larsson, O. Selroos. (CERS Journals Ltd 1998.

ABSTRACT: This randomized, double-blind, crossover study in two parts compared tolerability to high doses of formoterol $\left(\right.$ Oxis $\AA$ Turbuhaler $\left.{ }^{\circledR}\right)$ with that of high doses of terbutaline (Bricanyl® Turbuhaler $\left.{ }^{\circledR}\right)$.

After Holter monitoring at home, 12 patients were treated with $4+4+4$ doses of formoterol Turbuhaler, $6 \mu \mathrm{g} \cdot \mathrm{dose}^{-1}$, (total daily metered dose $72 \mu \mathrm{g}$ ) or $4+4+4$ doses of terbutaline Turbuhaler, $0.5 \mathrm{mg} \cdot \mathrm{dose}^{-1}$ (daily dose $6 \mathrm{mg}$ ) given in the morning, after lunch and in the evening, for 3 consecutive days. After a one week washout period at home, patients received the alternative treatment. Thereafter, 15 other patients received 8+6+6 doses of formoterol Turbuhaler (total daily metered dose $120 \mu \mathrm{g}$ ) or $8+6+6$ doses of terbutaline Turbuhaler (daily dose $10 \mathrm{mg}$ ). Pulse, cardiac frequency, blood pressure, serum potassium, electrocardiogram and forced expiratory volume in one second (FEV1) were registered at regular intervals and Holter monitoring was applied during all 4 treatment days.

Terbutaline $6 \mathrm{mg}$ showed significantly greater systemic effects than formoterol 72 $\mu \mathrm{g}$ on pulse, blood pressure, cardiac frequency and QTc (QT interval corrected for heart rate). Terbutaline $10 \mathrm{mg}$ had significantly greater effects than formoterol 120 $\mu \mathrm{g}$ on serum potassium levels, pulse, cardiac frequency and QTc. No differences in FEV1 levels were found. Both drugs were safe and generally well tolerated on both dose levels.

In conclusion, high doses of formoterol Turbuhaler over 3 days were generally safe and well tolerated. Daily doses of $6 \mathrm{mg}$ and $10 \mathrm{mg}$ terbutaline Turbuhaler were systemically more potent than $72 \mathrm{\mu g}$ and $120 \mathrm{\mu g}$ formoterol, respectively. The safety margin thus appears to be wide if patients happen to use extra doses of formoterol in addition to those prescribed for regular use.

Eur Respir J 1998; 12: 573-579.
*Mjölbolsta Hospital, Karis, Finland. ${ }^{+}$Clinical R\&D, Astra Draco AB, Lund, Sweden.

Correspondence: O. Selroos

Astra Draco AB

P.O. Box 34

S-22100 Lund

Sweden

Fax: 4646337575

Keywords: Asthma

electrocardiogram

formoterol

potassium

terbutaline

Turbuhaler

Received: October 291997

Accepted after revision March 211998
Formoterol is a selective $\beta_{2}$-adrenoceptor agonist with a low affinity for $\beta_{1}$-adrenoceptors [1]. While oral formoterol has a duration of bronchodilatation similar to that of short-acting $\beta_{2}$-agonists, the duration is significantly prolonged to about $12 \mathrm{~h}$ when the substance is given by inhalation [2]. Inhaled formoterol, like the other longacting inhaled bronchodilator salmeterol, consequently has a place in asthma therapy when, for example, daytime or night-time symptom control and exercise tolerance are not achieved with short-acting bronchodilators in combination with anti-inflammatory medication.

In contrast to salmeterol, formoterol exhibits a rapid onset of action similar to that seen after inhalation of short-acting $\beta_{2}$-agonists [3-5]. Because of the quick onset, patients may, by mistake or on purpose, take extra inhalations of formoterol instead of a prescribed short-acting rescue drug for inhalation, such as salbutamol or terbutaline. It is therefore important to evaluate the systemic effects of formoterol Turbuhaler in doses much higher than those approved for regular use, i.e. 6-12 $\mu \mathrm{g}$ b.i.d. (corresponding to 4.5-9 $\mu \mathrm{g}$ b.i.d. delivered dose). In order to obtain maximum bronchodilatation, some patients may need 24 $\mu \mathrm{g}$ b.i.d. (18 $\mu \mathrm{g}$ b.i.d. delivered dose), which is the highest recommended daily formoterol Turbuhaler dose for regular use.

Formoterol via a pressurized metered-dose inhaler (pMDI) has already been given to 13 asthmatics at cumulative doses of $12+24+48+(48)+(48)+(48) \mu \mathrm{g}$ at $60 \mathrm{~min}$ intervals [6]. Administration was stopped earlier if a maximum bronchodilatation was achieved. The maximum individual doses were $84 \mu \mathrm{g}$ in six patients, $132 \mu \mathrm{g}$ in three, $180 \mu \mathrm{g}$ in three and $228 \mu \mathrm{g}$ in one patient. No major changes were observed in serum potassium levels. Another study in 12 healthy subjects compared the cardiovascular and metabolic effects of $5 \times 24 \mu \mathrm{g}$ formoterol pMDI given at $30 \mathrm{~min}$ intervals (total dose $120 \mu \mathrm{g}$ ) with those of total doses of 2,000 $\mu \mathrm{g}$ salbutamol, 2,000 $\mu \mathrm{g}$ fenoterol and placebo [7]. Fenoterol had the most pronounced systemic effects. Formoterol and salbutamol showed similar maximum cardiovascular and potassium-lowering effects, but the duration of the formoterol-induced effects was slightly longer.

This study was designed to evaluate the tolerability and safety of high doses of formoterol delivered via the 
inspiratory flow-driven, dry powder inhaler, Turbuhaler®, compared with an equal number of inhalations of terbutaline, also delivered via Turbuhaler. The doses were given during 3 consecutive days and were divided into three administrations per day.

\section{Materials and methods}

\section{Subjects}

Outpatients of both sexes, aged $\breve{S} 18$ yrs, suffering from asthma defined according to American Thoracic Society (ATS) criteria [8], could enter the study. Patients were required to have had diagnosed asthma for 6 months or more and a basal forced expiratory volume during one second (FEV1) Š40\% predicted normal value. Serum potassium level at baseline was to be within the hospital's reference range, $3.7-5.3 \mathrm{mmol} \cdot \mathrm{L}^{-1}$. Patients were required to have been on regular treatment with an inhaled glucocorticosteroid at constant dosage 4 weeks prior to inclusion and to need regular treatment with short-acting inhaled $\beta_{2}$-agonists. They had to give informed consent in writing before any study-related procedures were initiated. Patients could not be included if they showed evidence of concomitant diseases or baseline laboratory test values outside the reference ranges, which might constitute a risk for the patient. Pregnant or lactating females were excluded, as were patients using asthma medications other than inhaled glucocorticosteroids, disodium cromoglycate, antihistamines, anticholinergics and short-acting inhaled $\beta_{2}$-agonists, which were allowed.

\section{Study design}

The study was randomized and double-blind and had a crossover design. Each patient received formoterol or terbutaline for 3 days and then, after a one week washout period, the alternative treatment for 3 days. The study consisted of a run-in period and two randomized treatment periods. There was a one week washout period between the treatments and a follow-up visit one week after the end of the second treatment period. During the run-in period and the washout period, patients used terbutaline Turbuhaler $0.5 \mathrm{mg}$ q.i.d. (daily dose $2 \mathrm{mg}$ ) in order to obtain a uniform baseline for the treatment periods.

During the run-in phase, Holter monitoring was applied for $24 \mathrm{~h}$ at home. Patients without electrocardiographic (ECG) abnormalities and with QTc (QT interval corrected for heart rate) $<450 \mathrm{~ms}$ were accepted for the study.

For safety reasons, the study was performed in two parts with an interim analysis after part A. A new patient population was recruited for part B. At visits 2 and 3, the patients stayed in the coronary care unit (CCU) for the first night and were not allowed to leave the unit during daytime. Patients could spend the night at home.

Part A. Patients received 4+4+4 doses daily of formoterol Turbuhaler $6 \mu \mathrm{g}$ (metered dose, corresponding to $4.5 \mu \mathrm{g}$ delivered dose), total daily dose $72 \mu \mathrm{g}$, or 4+4+4 doses of terbutaline Turbuhaler, $0.5 \mathrm{mg} \cdot \mathrm{dose}^{-1}$, total daily dose 6 $\mathrm{mg}$ for 3 consecutive days. The daily dose was divided into three administrations which were given in the morn- ing, at lunchtime and in the evening. The single doses were given at 5 min intervals: the morning doses approximately at 07:30, 07:35, 07:40 and 07:45 h. Lunchtime dosing started at 13:00 $\mathrm{h}$ and evening dosing at 18:30 h. A separate terbutaline Turbuhaler inhaler was used as rescue medication when necessary.

Part B. Patients received $8+6+6$ doses of $6 \mu \mathrm{g}$ formoterol Turbuhaler, total daily dose $120 \mu \mathrm{g}$, or $8+6+6$ doses of $0.5 \mathrm{mg}$ terbutaline Turbuhaler, total daily dose $10 \mathrm{mg}$. At each time point, patients inhaled two doses of the study medication. Morning dosing thus consisted of two doses at approximately 07:30, 07:35, 07:40 and 07:45 h. At lunchtime and in the evening, two doses were given three times at 5 min intervals, starting at 13:00 $\mathrm{h}$ and 18:30 $\mathrm{h}$.

\section{Methods}

Before the treatment periods the patients stayed overnight in the CCU and were not allowed to leave the hospital during the 3 clinic days. Assessments were not allowed to differ by $> \pm 1 \mathrm{~h}$ for an individual patient. The patients were not to have taken any rescue medication within $6 \mathrm{~h}$ before the first measurement on day 1 .

Physical examination was performed according to standard routines, in which weight and height, general appearance, lymph nodes, thyroid gland, heart, lungs and abdomen were assessed.

Spirometry (forced vital capacity (FVC) and FEV1) was performed with a Vitalograph Alpha spirometer (Vitalograph Ltd., Buckingham, UK). Values were obtained 15 min before and 15 min after the last dose of each treatment interval. The highest value of three measurements was selected.

Samples for the measurement of serum potassium were taken $15 \mathrm{~min}$ before the first dose, 1, 2 and $4 \mathrm{~h}$ after the last dose in each treatment interval and on the morning following the third treatment day. The samples were analysed at the hospital's clinical laboratory according to established routines.

Pulse and blood pressure were measured 15 min before the first drug administration, 1, 2 and $4 \mathrm{~h}$ after the last dose in each treatment interval and on the morning following the third treatment day. After a 5 min rest in a supine position, pulse was measured by palpation of the radial artery for $30 \mathrm{~s}$. Systolic and diastolic blood pressures were measured using the cuff method.

A 12-lead resting ECG was recorded $15 \mathrm{~min}$ before the first dose, $1 \mathrm{~h}$ after the last dose in each treatment interval and on the morning following the third treatment day. The ECG recordings were analysed at the Department of Clinical Physiology, Sahlgrenska Hospital, Gothenburg, Sweden. The ECG were analysed with regard to cardiac frequency, PR interval, QRS duration, QT interval, QTc, ST-T changes and all findings associated with rhythm. An overall interpretation of the ECG was made.

Holter monitoring was performed during a $24 \mathrm{~h}$ baseline period and continuously for $72 \mathrm{~h}$ during the treatment periods. The results will be reported separately.

At the first and final visits, routine laboratory safety tests for haematology, clinical chemistry tests and urine analysis were performed.

Adverse events were recorded by means of a standard question to the patients at the clinic visits: "Have you had 
any health problems since the last visit/last questioning?" Spontaneously reported adverse events and the patient's response to this question were recorded with information about seriousness, intensity, date and time of onset, date and time of recovery and action taken.

The study was conducted in accordance with the Declaration of Helsinki and the principles of Good Clinical Practice. Approval was obtained from the Ethics Committee of Mjölbolsta Hospital and the Finnish drug regulatory authorities before the start of the study.

\section{Analyses}

Pharmacodynamic evaluation. In order to describe serum potassium concentrations, pulse, blood pressure and ECG data over $24 \mathrm{~h}$, the following variables were calculated: the lowest serum potassium concentration $(C \mathrm{~min})$; the highest value (Emax) observed for pulse, systolic blood pressure, cardiac frequency, QTc and FEV1; the lowest value (Emin) observed for diastolic blood pressure, PR interval and QT interval.

Statistical analyses. The maximum effect on each day, as defined by the pharmacodynamic parameters given above, was calculated for each patient and treatment. For each variable, an additive analysis of variance (ANOVA) model with patient, period, treatment, day and the interaction between treatment and day as fixed factors, and baseline (the predrug measurement on day 1) as covariate, was fitted to the data. Parts A and B of the study were analysed separately. The two treatments in each study were compared, both regarding mean effects over 3 days and for each day separately. In addition, the difference in effects between days was investigated by considering the effect of the factor "day". The question of different time profiles for the two drugs was addressed by considering the effect of the treatment $\times$ day interaction factor.

For FEV1 a multiplicative ANOVA model was used instead of an additive one, i.e. data were log-transformed before analysis.

The ECG recordings included information about rhythm, extrasystoles, ST-T changes and an overall evaluation. Abnormal findings were tabulated without any statistical analyses.

\section{Results}

\section{Patients}

Thirty patients, 15 in each part, were enrolled in the study. In part A, two patients were not randomized; one withdrew consent and one was not eligible. Six patients started with formoterol and seven with terbutaline. One of the formoterol patients was withdrawn because of an adverse event (atrial fibrillation). Thus, 12 patients completed part A of the study. In part B, eight patients started on formoterol and seven on terbutaline. In the second treatment phase, after crossing over, one of the formoterol patients did not return to the hospital on the scheduled day. Thus, 14 patients completed part B of the study.

The mean \pm SD age of the patients was $59 \pm 6$ (range $45-$ 67 ) yrs in part A and 56 \pm 9 (range 38-73) yrs in part B. In part A there were four males and eight females and in part B 11 males and four females. All patients were Caucasian and the 12 female patients were all postmenopausal.

The mean \pm SD FEV 1 at baseline was $2.20 \pm 0.63 \mathrm{~L}$ for part A patients and $2.61 \pm 0.71 \mathrm{~L}$ for part $\mathrm{B}$ patients, corresponding to $82 \%$ predicted values for both groups. At visit 1 , the mean pulse rate was $72 \pm 5$ beats. $\mathrm{min}^{-1}$ in group $\mathrm{A}$ and $71 \pm 10$ beats. $\mathrm{min}^{-1}$ in group B patients. The mean blood pressures were $150 / 90 \pm 15 / 10 \mathrm{mmHg}$ and $144 / 87 \pm$ $17 / 10 \mathrm{mmHg}$, respectively. All ECG were interpreted as normal in part $\mathrm{A}$. In part B, one patient had a slight conduction abnormality which was not considered an exclusion criterion.

\section{Serum potassium}

Serum potassium concentrations at baseline were within the normal range, $3.7-5.3 \mathrm{mmol} \cdot \mathrm{L}^{-1}$, in all patients. The mean, minimum, median and maximum serum potassium concentrations over the three study days and after the study are shown separately for parts A and B in tables 1 and 2 and in figures 1 and 2. The potassium-lowering effect diminished over time.

In part $\mathrm{A}$, during treatment with formoterol Turbuhaler $72 \mu \mathrm{g} \cdot$ day $^{-1}$, five patients had values below the lower limit of the reference range, $3.7 \mathrm{mmol} \cdot \mathrm{L}^{-1}$, on day 1 , three patients on day 2 and one patient on day 3. During treatment with terbutaline $6 \mathrm{mg} \cdot \mathrm{day}^{-1}$, the corresponding numbers were seven, six and four, respectively.

In part $\mathrm{B}$, during treatment with formoterol Turbuhaler $120 \mu \mathrm{g} \cdot$ day $^{-1}, 10$ patients had values below the reference range on day 1 , six on day 2 , and five on day 3 . During treatment with terbutaline Turbuhaler $10 \mathrm{mg} \cdot$ day $^{-1}$, the corresponding numbers were 12,10 and nine patients.

The statistical comparison showed no significant difference between the mean potassium-lowering effect of 72 $\mu \mathrm{g}$ formoterol Turbuhaler and $6 \mathrm{mg}$ terbutaline Turbuhaler over 3 days. The difference (table 3 ) was $0.03 \mathrm{mmol} \cdot \mathrm{L}^{-1}$.

Table 1. - Serum potassium mean, SD, minimum, median and maximum values at baseline, during (days 1-3) and after (day 4) treatment in part A of the study

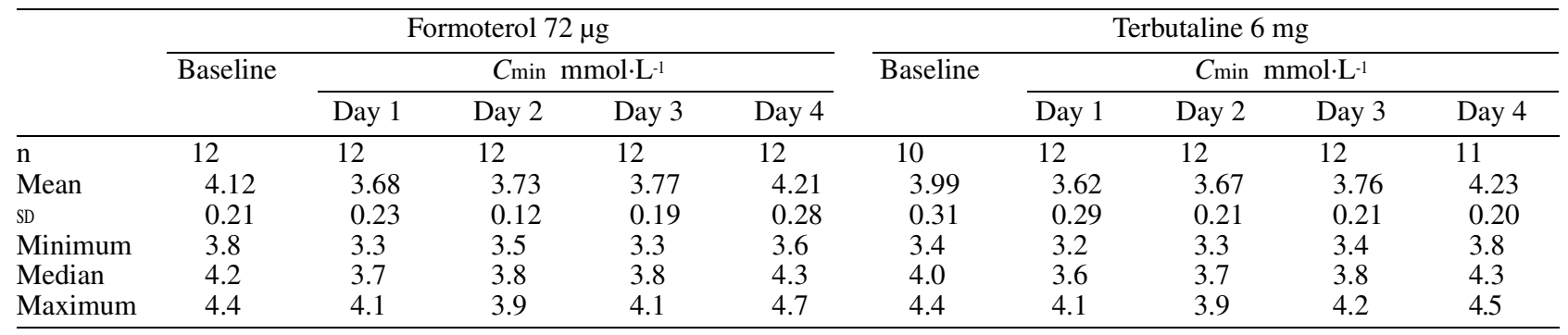

Cmin: lowest serum potassium concentration $\left(\mathrm{mmol} \cdot \mathrm{L}^{-1}\right)$. 
Table 2. - Serum potassium mean, sD, minimum, median and maximum values at baseline, during (days 1-3) and after (day 4) treatment in part B of the study

\begin{tabular}{|c|c|c|c|c|c|c|c|c|c|c|}
\hline & \multicolumn{5}{|c|}{ Formoterol $120 \mu \mathrm{g}$} & \multicolumn{5}{|c|}{ Terbutaline $10 \mathrm{mg}$} \\
\hline & \multirow[t]{2}{*}{ Baseline } & \multicolumn{4}{|c|}{$C_{\min } \mathrm{mmol} \cdot \mathrm{L}^{-1}$} & \multirow[t]{2}{*}{ Baseline } & \multicolumn{4}{|c|}{$C \min \mathrm{mmol} \cdot \mathrm{L}^{-1}$} \\
\hline & & Day 1 & Day 2 & Day 3 & Day 4 & & Day 1 & Day 2 & Day 3 & Day 4 \\
\hline $\mathrm{n}$ & 15 & 15 & 15 & 15 & 15 & 14 & 15 & 15 & 15 & 14 \\
\hline Mean & 3.79 & 3.44 & 3.61 & 3.72 & 4.11 & 3.77 & 3.31 & 3.47 & 3.55 & 4.11 \\
\hline SD & 0.32 & 0.31 & 0.27 & 0.23 & 0.25 & 0.30 & 0.36 & 0.26 & 0.26 & 0.22 \\
\hline Minimum & 3.1 & 3.0 & 3.1 & 3.2 & 3.5 & 3.3 & 2.6 & 3.0 & 3.1 & 3.8 \\
\hline Median & 3.8 & 3.4 & 3.7 & 3.7 & 4.1 & 3.8 & 3.4 & 3.4 & 3.5 & 4.1 \\
\hline Maximum & 4.4 & 3.9 & 4.0 & 4.1 & 4.4 & 4.4 & 3.8 & 3.8 & 3.9 & 4.5 \\
\hline
\end{tabular}

Cmin: lowest serum potassium concentration $\left(\mathrm{mmol} \cdot \mathrm{L}^{-1}\right)$.

(95\% confidence interval $(\mathrm{CI})-0.04$ to 0.10$)$. Terbutaline $10 \mathrm{mg}$, however, decreased the mean $C$ min during all 3 treatment days more than formoterol Turbuhaler $120 \mu \mathrm{g}$. The mean values were $0.12,0.13$ and $0.15 \mathrm{mmol} \cdot \mathrm{L}^{-1}$ lower after treatment with terbutaline. The mean value over the 3 days was $0.13 \mathrm{mmol} \cdot \mathrm{L}^{-1}$ lower in the terbutaline group, which was significantly different from the mean decrease in the formoterol group (CI 0.05 to 0.21 ). No difference in the potassium profiles over the 3 study days was found between formoterol and terbutaline, but the changes from one study day to the next were statistically significant for both drugs in both parts of the study.

\section{Systolic blood pressure}

In part $\mathrm{A}$, the mean maximal systolic blood pressure (Emax) increased in the formoterol $72 \mu \mathrm{g}$ group from a baseline of 149.6 to $155.0 \mathrm{mmHg}$ on day 1 and in the terbutaline $6 \mathrm{mg}$ group from $139.2 \mathrm{mmHg}$ (baseline) to $153.3 \mathrm{mmHg}$ on day 3 . The difference in mean increase in systolic blood pressure over 3 days between the groups, $-5.0 \mathrm{mmHg}$, was statistically significant (CI -9.2 to -0.8 ).

In part $\mathrm{B}$, the mean maximum increase in the formoterol $120 \mu \mathrm{g}$ group was from a baseline of 134.0 to 145.3 $\mathrm{mmHg}$ on day 1 and in the terbutaline $10 \mathrm{mg}$ group from $131.3 \mathrm{mmHg}$ at baseline to $141.3 \mathrm{mmHg}$ on day 1 . The difference in mean increase between these two groups, 0.6 $\mathrm{mmHg}$, was not statistically significant (CI -1.9 to 3.1).

The systolic blood pressure decreased from day 1 to day 3. In both parts, the difference between the days was

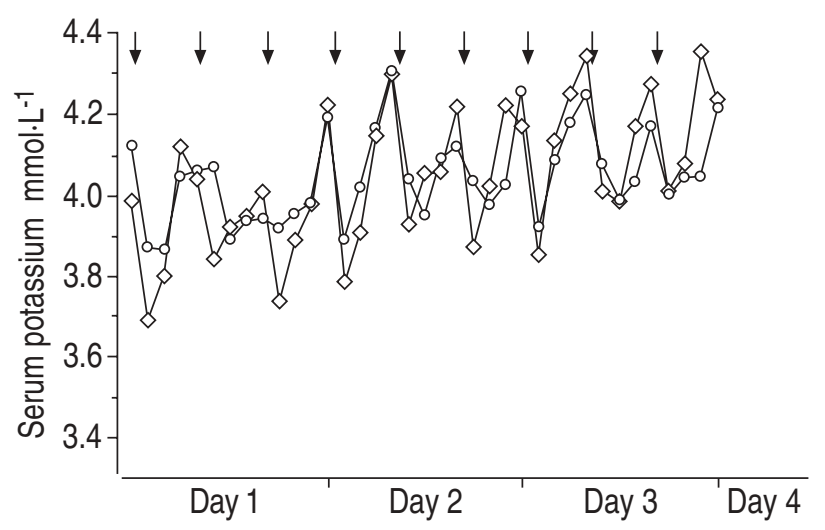

Fig. 1. - Mean serum potassium values before, during the 3 treatment days and after treatment (day 4 ) in patients receiving $72 \mu \mathrm{g}$ formoterol $(\circ)$ or $6 \mathrm{mg}$ terbutaline $(\diamond)$ daily via Turbuhaler (part A of the study). The arrows represent the dosing times. statistically significant. The time profile was also different between the drugs in the two parts. In both parts, no difference between treatments could be seen on days 1 and 3, but on day 2 , the terbutaline doses resulted in significantly greater increases than the formoterol doses.

\section{Diastolic blood pressure}

In part $\mathrm{A}$, the mean minimum diastolic blood pressure (Emin) decreased in the formoterol group from 86.3 at baseline to $69.6 \mathrm{mmHg}$ on both day 2 and day 3, and in the terbutaline group from $84.6 \mathrm{mmHg}$ at baseline to 66.2 $\mathrm{mmHg}$ on day 2. The difference between the groups in mean decrease over 3 days, $2.7 \mathrm{mmHg}$, was statistically significant (CI 0.3 to 5.2 ).

In part $\mathrm{B}$, the mean minimum diastolic blood pressure decreased in the formoterol group from 82.0 to 66.0 $\mathrm{mmHg}$ on day 2 and in the terbutaline group from 77.7 to $65.7 \mathrm{mmHg}$ on both day 1 and day 3 . The difference between the groups in mean decrease over 3 days in diastolic blood pressure, $0.7 \mathrm{mmHg}$, was not statistically significant (CI -1.3 to 2.8 ).

No significant difference between the days was found for the decrease in diastolic blood pressure, nor was there a difference between the time profiles of the two drugs.

\section{Electrocardiographic findings}

Cardiac frequency. The mean ECG-based cardiac frequencies during the study are shown in figure 3. In part A,

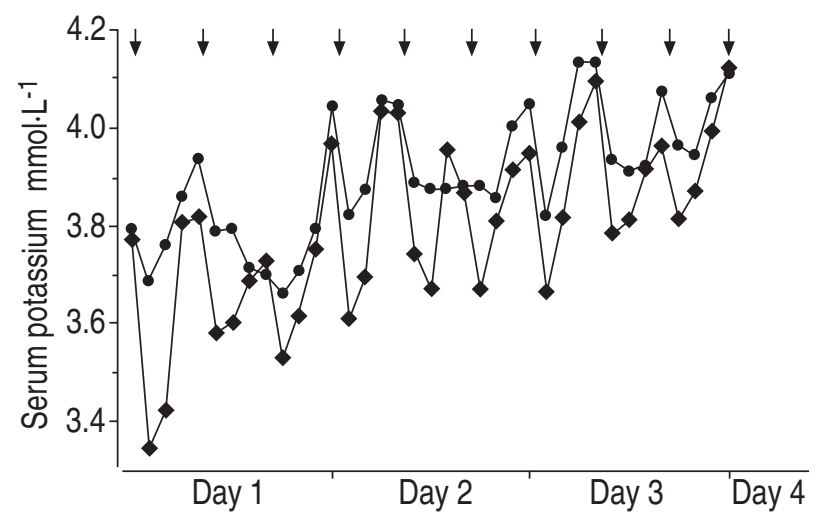

Fig. 2. - Mean serum potassium values in patients receiving $120 \mu \mathrm{g}$ formoterol $(\bullet)$ or $10 \mathrm{mg}$ terbutaline $(\bullet)$ daily via Turbuhaler (part B of the study). The arrows represent the dosing times. 
Table 3. - Daily comparisons between serum potassium values during treatment with formoterol Turbuhaler $72 \mu \mathrm{g}$ versus terbutaline Turbuhaler $6 \mathrm{mg}$ and formoterol Turbuhaler $120 \mu \mathrm{g}$ versus terbutaline Turbuhaler $10 \mathrm{mg}$

\begin{tabular}{llrr}
\hline Difference & & $\begin{array}{c}\text { Mean } \\
\text { value }\end{array}$ & 95\% CI \\
\hline Formoterol 72 $\mu \mathrm{g} /$ & Mean over 3 days & 0.03 & $-0.04-0.10$ \\
terbutaline 6 mg & Day 1 & 0.04 & $-0.08-0.17$ \\
& Day 2 & 0.05 & $-0.07-0.18$ \\
& Day 3 & -0.01 & $-0.15-0.12$ \\
Formoterol 120 $\mu \mathrm{g} /$ & Mean over 3 days & 0.13 & $0.5-0.21$ \\
terbutaline 10 mg & Day 1 & 0.12 & $-0.02-0.25$ \\
& Day 2 & 0.13 & $-0.01-0.26$ \\
& Day 3 & 0.15 & $0.02-0.29$ \\
\hline
\end{tabular}

CI: confidence interval.

the mean maximum cardiac frequency increased in the formoterol group from 60.6 beats. $\mathrm{min}^{-1}$ at baseline to 79.1 beats. $\mathrm{min}^{-1}$ on day 3 and in the terbutaline group from 63.0 beats. $\mathrm{min}^{-1}$ at baseline to 86.4 beats $\cdot \mathrm{min}^{-1}$ on day 2 . The difference between the treatments in mean change over the 3 days, -6.2 beats $\cdot \mathrm{min}^{-1}$, was statistically significant (CI -9.1 to -3.3).

In part $\mathrm{B}$, the mean maximum cardiac frequency increased in the formoterol group from 64.8 beats. min $^{-1}$ at baseline to 78.1 beats $\cdot \mathrm{min}^{-1}$ on day 3 and in the terbutaline group from 62.7 beats $\cdot \mathrm{min}^{-1}$ at baseline to 86.3 beats $\cdot \mathrm{min}^{-1}$ on day 3 . The difference between the treatments in mean change in heart rate over 3 days, -8.2 beats $\cdot \mathrm{min}^{-1}$, was statistically significant (CI -11.1 to -5.3$)$.

In part $\mathrm{A}$, the increase in cardiac frequency showed a significant difference between the days for both drugs. In part B, a similar increasing trend was seen, but the differences between the days did not reach statistical significance. No difference between the time profiles of the drugs was detectable.

QTc. The mean QTc values during the study are shown in figure 4. In part A, the maximum mean increase in QTc in the formoterol $72 \mu \mathrm{g}$ group was from $414.0 \mathrm{~ms}$ at baseline to $432.7 \mathrm{~ms}$ on day 1 . In the terbutaline $6 \mathrm{mg}$ group, the mean increase was from $417.2 \mathrm{~ms}$ at baseline to 445.5 $\mathrm{ms}$ on day 1 . The mean difference between the treatments over 3 days, $-9.3 \mathrm{~ms}$, was statistically significant (CI -16.0 to -2.6$)$.

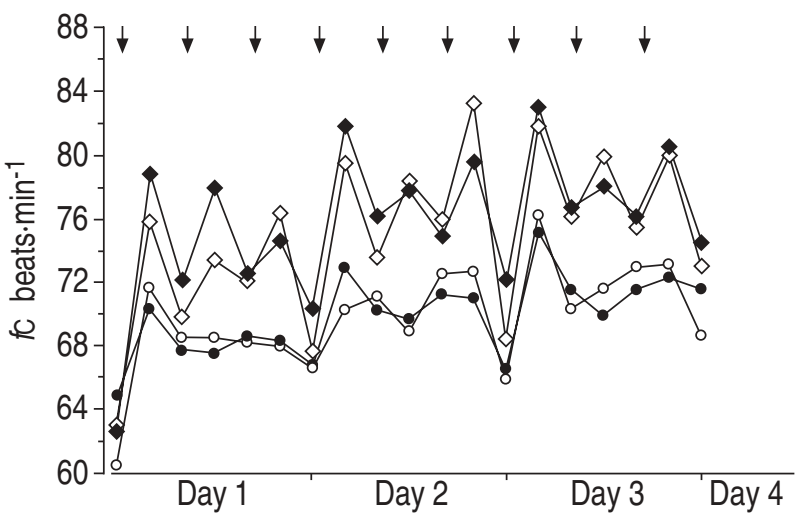

Fig. 3. - Mean cardiac frequency $(f \mathrm{c})$ before, during the 3 treatment days and after treatment (day 4) in patients receiving 72 (o) or $120 \mu \mathrm{g}$ $(\bullet)$ of formoterol and $6(\diamond)$ or $10 \mathrm{mg}(\diamond)$ of terbutaline via Turbuhaler. The arrows represent the dosing times.

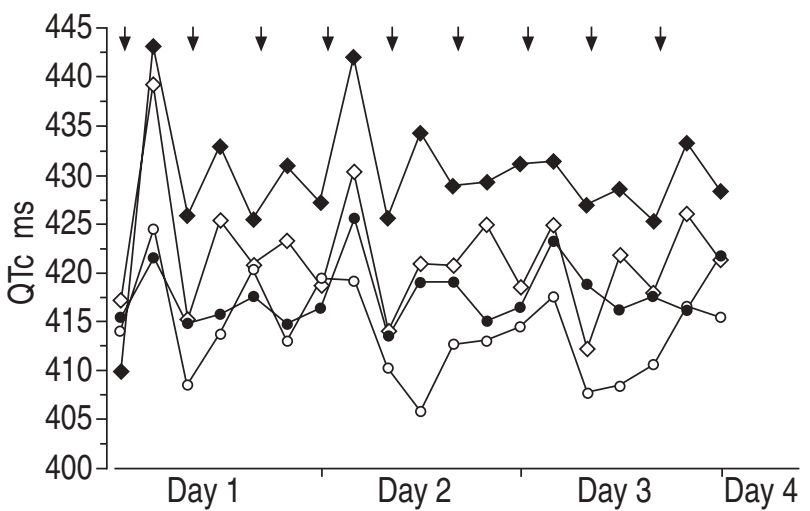

Fig. 4. - Mean QT interval corrected for heart rate (QTc) values before, during the 3 treatment days and after treatment (day 4) in patients receiving $72(\circ)$ or $120 \mu \mathrm{g}(\bullet)$ of formoterol and $6(\diamond)$ or $10 \mathrm{mg}$ $(\diamond)$ of terbutaline via Turbuhaler. The arrows represent the dosing time.

In part $\mathrm{B}$, the maximum mean increase in QTc in the formoterol $120 \mu \mathrm{g}$ group was from $415.4 \mathrm{~ms}$ at baseline to $432.4 \mathrm{~ms}$ on day 2 . In the terbutaline $10 \mathrm{mg}$ group, the mean increase was from $409.9 \mathrm{~ms}$ at baseline to 449.9 $\mathrm{ms}$ on day 2 . The mean difference between the treatments over 3 days, $-20.6 \mathrm{~ms}$, was statistically significant $(\mathrm{CI}$ -27.2 ; to -14.1 ).

No statistically significant differences in QTc intervals were seen between the days. The time profiles were also similar for both drugs.

$F E V 1$. All four high-dose bronchodilator treatments, formoterol $72 \mu \mathrm{g}$ and $120 \mu \mathrm{g}$ and terbutaline $6 \mathrm{mg}$ and $10 \mathrm{mg}$ daily during 3 days, resulted in very similar mean maximum increases in FEV1 (fig. 5). In part A, the mean \pm SD baseline $\mathrm{FEV}_{1}$ was $2.03 \pm 0.51 \mathrm{~L}$ in the formoterol $72 \mu \mathrm{g}$ period and increased to a maximum of $2.46 \pm 0.53 \mathrm{~L}$. The corresponding values in the terbutaline $6 \mathrm{mg}$ period were $1.99 \pm 0.54 \mathrm{~L}$ and $2.47 \pm 0.64 \mathrm{~L}$, respectively. In part B the mean baseline FEV1 was $2.44 \pm 0.66 \mathrm{~L}$ in the formoterol $120 \mu \mathrm{g}$ period and increased to a maximum of $2.85 \pm 0.72$ L. The corresponding values in the terbutaline $10 \mathrm{mg}$ period were $2.45 \pm 0.72 \mathrm{~L}$ and $2.81 \pm 0.80 \mathrm{~L}$, respectively.

Adverse events. One adverse event in the study was classified as serious: a patient in the $72 \mu \mathrm{g}$ formoterol group had

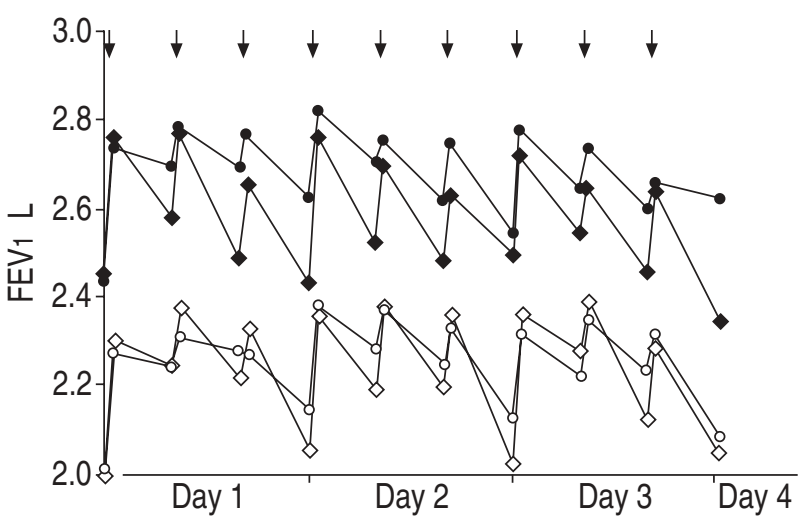

Fig. 5. - Mean forced expiratory volume in one second (FEV1) values before, during the 3 treatment days and after treatment (day 4 ) in patients receiving $72(\circ)$ or $120 \mu \mathrm{g}(\bullet)$ of formoterol and $6(\diamond)$ or $10 \mathrm{mg}$ $(\diamond)$ of terbutaline via Turbuhaler. The arrows represent the dosing time. 
Table 4. - Most frequently reported adverse events

\begin{tabular}{|c|c|c|c|c|c|c|c|c|}
\hline & \multicolumn{2}{|c|}{$\begin{array}{c}\text { Formot. } \\
72 \mu \mathrm{g}\end{array}$} & \multicolumn{2}{|c|}{$\begin{array}{c}\text { Terbuta. } \\
6 \mathrm{mg}\end{array}$} & \multicolumn{2}{|c|}{$\begin{array}{l}\text { Formot. } \\
120 \mu \mathrm{g}\end{array}$} & \multicolumn{2}{|c|}{$\begin{array}{c}\text { Terbuta. } \\
10 \mathrm{mg}\end{array}$} \\
\hline & $\mathrm{n}$ & $\%$ & $\mathrm{n}$ & $\%$ & $\mathrm{n}$ & $\%$ & $\mathrm{n}$ & $\%$ \\
\hline Muscular cramps & 3 & 23 & 0 & & 1 & 7 & 2 & 13 \\
\hline Cough & 1 & 8 & 0 & & 2 & 13 & 2 & 13 \\
\hline Fatigue & 0 & & 0 & & 2 & 13 & 1 & 7 \\
\hline Flu-like symptoms & 1 & 8 & 0 & & 0 & & 2 & 13 \\
\hline Diarrhoea & 0 & & 0 & & 2 & 13 & 0 & \\
\hline Headache & 1 & 8 & 4 & 33 & 1 & 7 & 3 & 20 \\
\hline Tremor & 0 & & 2 & 17 & 1 & 7 & 5 & 33 \\
\hline
\end{tabular}

Formot.: formoterol; Terbuta.: terbutaline.

an ECG-diagnosed atrial fibrillation on day 1 in the evening after the third dose of formoterol. The patient was subjectively free from symptoms and had no earlier ECGverified disturbances of heart rhythm. Treatment with 400 mg quinidine sulphate resulted in a normal sinus rhythm. The patient was withdrawn from the study although at that time the patient informed the study staff about previous subjective arrhythmias in association with intake of alcohol.

Nonserious adverse events were reported as follows. In part A, seven patients reported nine adverse events while treated with formoterol $72 \mu \mathrm{g}$ and six patients reported seven adverse events during treatment with terbutaline 6 mg. In part B, eight patients reported 11 adverse events during treatment with formoterol $120 \mu \mathrm{g}$ and 10 patients reported 22 adverse events while on treatment with $10 \mathrm{mg}$ terbutaline. The most frequently reported adverse events are shown in table 4.

\section{Discussion}

Inhaled formoterol has, so far, been investigated and approved for maintenance treatment in patients with asthma using anti-inflammatory medication on a regular basis. Adding formoterol to, for example, inhaled corticosteroids has resulted in significantly improved airway function, fewer symptoms, less use of rescue bronchodilators [9-12] and a significant decrease in severe and mild asthma exacerbations [13]. Patients prescribed formoterol experience a rapid onset of action. There is consequently a possibility that patients will start to use formoterol for temporary symptom relief in addition to the regular maintenance dosing. In a double-blind, crossover study in 16 patients with chronic asthma, formoterol (24 $\mathrm{gg}$ twice daily) and salbutamol ( $400 \mu \mathrm{g}$ twice daily) were given for 4 weeks each. The patients were allowed to use two extra doses from the same inhalers as rescue medication, if needed. The extra use was marginal and no concerns about the safety of the patients were raised [14]. Similar conclusions were drawn based on a parallel-group study in 35 patients who received formoterol $24 \mu \mathrm{g}$ twice daily and as necessary or $400 \mu \mathrm{g}$ salbutamol twice daily and as necessary [15]. Nevertheless, it appears important to study the systemic effects of doses of formoterol higher than those used for maintenance treatment, especially as only a few such studies in a small number of adults $[6,7]$ and children [16] have been reported.

This study evaluated the clinical safety of two highdose levels of formoterol given via Turbuhaler during 3 consecutive days. The daily doses, formoterol $72 \mu \mathrm{g}$ and $120 \mu \mathrm{g}$, were divided into three administrations over the day in order to mimic a possible clinical situation with patients taking extra inhaled medication for symptom relief. The study was double-blind and randomized and the same number of terbutaline inhalations administered via Turbuhaler was used for comparison. This resulted in daily doses of $6 \mathrm{mg}$ and $10 \mathrm{mg}$ of terbutaline, respectively.

The patients used terbutaline on a regular basis during the run-in and washout periods in order to obtain similar baseline values before each treatment period. This treatment, resulted in some degree of tolerance to the systemic $\beta_{2}$-receptor mediated effects. It could be assumed, however, that patients prescribed a long-acting $\beta_{2}$-agonist also frequently use short-acting $\beta_{2}$-agonists. The study design, therefore, also tried to mimic the clinical situation. Theophylline was not a permitted concomitant medication as this was the first high-dose safety study with formoterol Turbuhaler. The safety of the possible combined use of theophylline and high-dose formoterol Turbuhaler needs to be investigated in future studies.

The study shows that the same number of inhalations (formoterol $6 \mu \mathrm{g}$ or terbutaline $0.5 \mathrm{mg}$ ) from Turbuhaler did not result in equal systemic effects. Six milligrams of terbutaline caused more systemic effects than $72 \mu \mathrm{g}$ formoterol and, similarly, $10 \mathrm{mg}$ terbutaline was more potent than $120 \mu \mathrm{g}$ formoterol. This was true of almost all variables measured. In many countries formoterol is also available as a single capsule-based dry-powder inhaler (Aerolizer®, Novartis). In vitro data indicate a significantly higher pulmonary deposition with Turbuhaler than with Aerolizer (Astra Draco, data on file). It is therefore likely that the clinical efficacy of $6 \mu \mathrm{g}$ formoterol Turbuhaler corresponds to that of $12 \mu \mathrm{g}$ formoterol Aerolizer.

Patients used to taking a defined number of inhalations for acute symptom relief from one inhaler will probably also take the same number of doses from another inhaler. From that point of view, it is valuable to know that the same number of inhalations via Turbuhaler of formoterol gave less systemic activity than the same number of inhalations of terbutaline. However, the exact potency relationship between formoterol and terbutaline could not be estimated because of the study design used, i.e. two parts with different patient populations and only one dose of each drug in each part.

The largest differences in systemic effects between formoterol and terbutaline were obtained for serum potassium values, with $10 \mathrm{mg}$ terbutaline causing greater potassiumlowering effects than $120 \mu \mathrm{g}$ formoterol. Although all patients included were asthma patients on regular treatment with $\beta_{2}$-agonists, there was a gradual increase in potassium values over the 3 study days, probably indicating a further development of tolerance to the extrapulmonary effects. However, as no placebo group was included, this conclusion cannot be drawn with certainty.

An interesting finding in this study was that the systemic effects of formoterol had the same time profile as those of terbutaline. This indicates that formoterol is a short-acting $\beta_{2}$-agonist in all respects except for the long bronchodilatation seen after inhalation. This is also in agreement with the findings in another study where the rapid normalization of formoterol-induced hypokalaemia (after a cumulative dose of $18+18+36 \mu \mathrm{g}$ at 30 min intervals) followed the same time course as after cumulative 
doses of $300+300+600 \mu \mathrm{g}$ or $900+900+1,800 \mu \mathrm{g}$ of salbutamol [17].

In this study, high exposure of repeated inhalations of formoterol, $6 \mu \mathrm{g} \cdot \mathrm{dose}^{-1}$, resulted in fewer chronotropic, inotropic and electrophysiological effects than the same number of doses of terbutaline, $0.5 \mathrm{mg} \cdot \mathrm{dose}^{-1}$, delivered via Turbuhaler. However, neither the statistically significant changes nor the changes in the individual absolute values for serum potassium, pulse rate, blood pressure or ECG variables, with terbutaline giving more pronounced effects, were of a magnitude where patients would have been at a risk. As expected, no difference in FEV1 values could be found with these high bronchodilator doses.

It is concluded that both formoterol and terbutaline given in these very high doses over 3 days were well tolerated. The proportion of patients reporting adverse events was similar in the four treatment groups and the most frequently reported events were expected $\beta_{2}$-receptor-mediated effects. Atrial fibrillation occurred in one patient on day 1 after $72 \mu \mathrm{g}$ of formoterol, but this patient had a history of arrhythmias and should not have been included in the study.

Because of its rapid onset of action, formoterol Turbuhaler may be used as a rescue medication. The results of this study show that daily doses up to and including 120 $\mu \mathrm{g}$ (corresponding to $90 \mu \mathrm{g}$ delivered dose) are safe and well tolerated in patients with chronic asthma and without concomitant ischaemic heart disease, using $\beta_{2}$-agonists on a regular basis.

\section{References}

1. Decker N, Quennedey MC, Rouot B, Schwartz J, Velly J. Effects of $N$-aralkyl substitution of $\beta$-agonists on $\alpha$ - and $\beta$-adrenoceptor subtypes: pharmacological studies and binding assays. J Pharm Pharmacol 1982; 34: 107-112.

2. Löfdahl C-G, Svedmyr N. Formoterol fumarate, a new $\beta_{2}$-adrenoceptor agonist. Allergy 1989; 44: 264-271.

3. Derom EY, Pauwels RA. Time course of bronchodilating effect of inhaled formoterol, a potent and long-acting sympathomimetic. Thorax 1992; 47: 30-33.

4. Wegener T, Hedenström H, Melander B. Rapid onset of action of inhaled formoterol in asthmatic patients. Chest 1992; 102: 535-538.

5. Wallin A, Sandstrom T, Rosenhall L, Melander B. Time course and duration of bronchodilatation with formoterol dry powder in patients with stable asthma (Correction). Thorax 1993; 48: 611-614. Thorax 1993; 48: 1188.

6. Maesen FPV, Costongs R, Smeets JJ, Brombacher PJ, Zweers PGMA. The effect of maximal doses of formoterol and salbutamol from a metered dose inhaler on pulse rate, ECG, and serum potassium concentrations. Chest 1991; 99: 1367-1373.

7. Bremner P, Woodman K, Burgess C, et al. A comparison of the cardiovascular and metabolic effects of formoterol, salbutamol and fenoterol. Eur Respir J 1993; 6: 204-210.

8. American Thoracic Society. Standards for the diagnosis and care of patients with chronic obstructive pulmonary disease (COPD) and asthma. Am Rev Respir Dis 1987; 136: 225-244.

9. Schreurs AJM, Sinninghe Damste HEJ, de Graaff CS, Greefhorst APM. A dose-response study with formoterol Turbuhaler as maintenance therapy in asthmatic patients. Eur Respir Dis 1996; 9: 1678-1683.

10. Brusasco V, Ringdal N, Ekström T, Sobradillo V. Effect of formoterol $6 \mu \mathrm{g}$ b.i.d. via Turbuhaler for 3 months in asthma: comparison with terbutaline and placebo. Eur Respir Dis 1995; 8: Suppl. 19, 58s.

11. Ekström T, Ringdal N, Tukiainen P. Formoterol Turbuhaler $12 \mu \mathrm{g}$ b.i.d. improves lung function in asthmatic patients compared with terbutaline and placebo. Eur Respir Dis 1995; 8: Suppl. 19, 157s.

12. van der Molen T, Postma DS, Turner MO, et al. Effects of the long-acting $\beta$ agonist formoterol on asthma control in asthmatic patients using inhaled corticosteroids. Thorax 1997; 52: 535-539.

13. Pauwels RA, Löfdahl C-G, Postma DS, et al. Effect of inhaled formoterol and budesonide on asthma exacerbations. N Engl J Med 1997; 337: 1405-1411.

14. Wallin A, Melander B, Rosenhall L, Sandström T, Wåhlander L. Formoterol, a new long acting beta 2 agonist for inhalation twice daily, compared with salbutamol in the treatment of asthma. Thorax 1990; 45: 259-261.

15. Midgren B, Melander B, Persson G. Formoterol, a new long-acting $\beta_{2}$ agonist, inhaled twice daily, in stable asthmatic subjects. Chest 1992; 101: 1019-1022.

16. Foucard T, Lönnerholm G. A study with cumulative doses of formoterol and salbutamol in children with asthma. Eur Respir Dis 1991; 4: 1174-1177.

17. Lötvall J, Persson G, Larsson P, Mardell C, Rosenborg J. Tolerability of inhaled high doses of formoterol and salbutamol in asthmatic patients maintained on twice daily formoterol $12 \mu \mathrm{g}$ (9 $\mu \mathrm{g}$ delivered). Eur Respir Dis 1997; 10: Suppl. 25, 103s. 